\title{
The experiences of children and adolescents living with ADHD were reflected in 6 themes
}

Kendall J, Hatton D, Beckett A, et al. Children's accounts of attention-deficit/hyperactivity disorder. ANS Adv Nurs Sci 2003;26: $114-30$.

\section{Q What are the experiences of children and adolescents living with attention deficit hyperactivity disorder (ADHD)?}

DESIGN

Qualitative study.

\section{SETTING}

Portland, Oregon and San Diego, California, USA.

\section{PATIENTS}

39 children and adolescents with ADHD (age range 6-17 y; 67\% boys; $38 \%$ African-American, 33\% Hispanic, and 23\% Caucasian) were recruited through advertisements and visits to ethnically diverse clinics, schools, and cultural support agencies.

\section{METHODS}

Children participated in indepth, semistructured interviews of 15-45 minutes. Observations of family relational patterns and environments were documented in field notes or as family portraits. Interviews were audiotaped, transcribed, and analysed using constant comparative analysis.

\section{MAIN FINDINGS}

6 themes were identified. (1) Problems. Most children reported everyday problems that got them "into trouble." They identified learning and cognition problems such as their "slower" rate of learning, feeling constantly distracted and confused about what was said to them, and being bored. Participants also identified behaviour problems in terms of difficulties following rules and getting along with others. Specific problems included fighting, throwing things, and yelling at teachers. Children also spoke of ADHD in terms of feeling sad, mad, frustrated, and ashamed. These emotional responses were often related to experiences of learning and behavioural problems. (2) Meaning and identity of $A D H D$. Children talked about ADHD in terms of "who" they were, rather than the symptoms they experienced. Most reported that ADHD meant being "hyper"-that is, "being out of control" and unable to "concentrate," "talking too much," and having a "hard time sitting down." Children frequently used the word "bad," and began to incorporate this idea into their identities. For others, ADHD meant "getting into trouble" or feeling "weird." Although most children believed they had ADHD, they did not construct it as an illness until an authority figure told them they had ADHD and legitimised the problem. Others did not see ADHD as an illness but simply as a "part of who they were" and that they were "different." (3) Pills. All participants took pills for ADHD at some time, and identified both positive and negative outcomes. Most children identified their medicine as the thing that helped them most; it helped them to control their hyperactivity and improved their concentration. Negative aspects included the bad taste, side effects such as headaches and stomachaches, and the fear and shame associated with taking pills to control behaviour. (4) Mom. Children identified their mothers as the person who helped them most. They

For correspondence: Dr J Kendall, School of Nursing, Oregon Health and Science University, Portland, OR, USA. kendaliu@ohsu.edu Source of funding: in part, National Institute of Nursing Research. worried about the effects of ADHD on their mothers and families. (5) Causes. 9 children said they did not know the cause, 5 said they were born with it, 4 thought it was "in the genes," 2 attributed it to maternal substance use during pregnancy, 1 related it to a birth accident, 1 thought it was a result of family tragedies she had experienced, and 1 thought it was caused by sports. (6) Ethnicity/race/ racism. African-American children described themselves as "bad" more often than Hispanic or Caucasian children, whereas Hispanic children described themselves in terms of "getting into trouble." Only Caucasian children talked about themselves as being "weird" or "whacko."

\section{CONCLUSION}

The experiences of children and adolescents with attention deficit hyperactivity disorder (ADHD) were reflected in 6 themes: problems in thinking, behaving, and feeling; meaning and identity; taking pills; the importance of Mom; causes of ADHD; and differences associated with ethnicity or race.

\section{Commentary}

M ore children are referred to mental health clinics for ADHD than for any other psychiatric or behavioural problem. The qualitative study by Kendall et al provides a unique perspective on this disorder by describing children's perceptions of living with ADHD. Across the 6 categories reported in the findings, attributes reflecting low self esteem are demonstrated. Research indicates that if children view themselves negatively, they tend to behave in negative ways. ${ }^{1}$ Studies have also shown a reciprocal relation between self esteem and delinquent behaviour: low self esteem fosters delinquency, and delinquency improves self esteem. ${ }^{2}$

The results of Kendall et al, coupled with the literature describing the effects of low self esteem on children's behaviour, suggest that interventions that enhance self esteem are important in the treatment of $A D H D$. Firstly, school nurses and paediatric nurses who regularly interact with children with ADHD have the opportunity to support children's views that $A D H D$ is an illness, not a personality trait, and that taking medication is the "smart" thing to do, not something to be associated with shame. Secondly, nurses who interact with families of children with ADHD can ease the burden of a child who worries about the impact of ADHD on the family by being a supportive listener and care educator for family members. Finally, school nurses can facilitate teachers' interactions with children with ADHD by helping them to design classroom management strategies based on rationales that recognise the reciprocal relation between self esteem and delinquent behaviour.

Lynda W Slimmer, RN, PhD University of Illinois at Chicago Chicago, Illinois, USA

1 Haynes NM. Influence of self-concept on school adjustment among middleschool students. J Soc Psychol 1990;130:199-207.

2 Rosenberg M, Schooler C, Schoenbach C. Self-esteem and adolescent problems: modeling reciprocal effects. American Sociological Review 1989;54:1004-18. 